Article

\title{
Silver Nanoparticle Conjugation-Enhanced Antibacterial Efficacy of Clinically Approved Drugs Cephradine and Vildagliptin
}

\author{
Abdulkader Masri ${ }^{1}$, Ayaz Anwar ${ }^{1}$, Dania Ahmed ${ }^{2}$, Ruqaiyyah Bano Siddiqui ${ }^{1}$, \\ Muhammad Raza Shah ${ }^{2}$ and Naveed Ahmed Khan $1, *$ (D) \\ 1 Department of Biological Sciences, School of Science and Technology, Sunway University, \\ Bandar Sunway 47500, Malaysia; abdul@gmail.com or 17025941@imail.sunway.edu.my (A.M.); \\ ayazanwarkk@yahoo.com (A.A.); ruqaiyyahs@sunway.edu.my (R.B.S.) \\ 2 HEJ Research Institute of Chemistry, International Center for Chemical and Biological Sciences, \\ University of Karachi, Karachi 74600, Pakistan; dania.ahmed48@yahoo.com (D.A.); \\ raza_shahm@yahoo.com (M.R.S.) \\ * Correspondence: naveed5438@gmail.com; Tel.: +60-(0)3-7491-8622 (ext. 7169); Fax: +60-(0)3-5635-8630
}

Received: 17 August 2018; Accepted: 19 October 2018; Published: 15 November 2018

\begin{abstract}
This paper sets out to determine whether silver nanoparticles conjugation enhance the antibacterial efficacy of clinically approved drugs. Silver conjugated Cephradine and Vildagliptin were synthesized and thoroughly characterized by ultraviolet visible spectrophotometry (UV-vis), Fourier transform infrared (FT-IR) spectroscopic methods, atomic force microscopy (AFM), and dynamic light scattering (DLS) analysis. Using antibacterial assays, the effects of drugs alone and drugs-conjugated with silver nanoparticles were tested against a variety of Gram-negative and Gram-positive bacteria including neuropathogenic Escherichia coli K1, Pseudomonas aeruginosa, Klebsiella pneumoniae, methicillin-resistant Staphylococcus aureus (MRSA), Bacillus cereus and Streptococcus pyogenes. Cytopathogenicity assays were performed to determine whether pretreatment of bacteria with drugs inhibit bacterial-mediated host cell cytotoxicity. The UV-vis spectra of both silver-drug nanoconjugates showed a characteristic surface plasmon resonance band in the range of 400-450 nm. AFM further confirmed the morphology of nanoparticles and revealed the formation of spherical nanoparticles with size distribution of 30-80 nm. FT-IR analysis demonstrated the involvement of Hydroxyl groups in both drugs in the stabilization of silver nanoparticles. Antibacterial assays showed that silver nanoparticle conjugation enhanced antibacterial potential of both Cephradine and Vildagliptin compared to the drugs alone. Pretreatment of bacteria with drugs inhibited E. coli K1-mediated host cell cytotoxicity. In summary, conjugation with silver nanoparticle enhanced antibacterial effects of clinically approved Cephradine. These findings suggest that modifying and/or repurposing clinically approved drugs using nanotechnology is a feasible approach in our search for effective antibacterial molecules.
\end{abstract}

Keywords: Cephradine; Vildagliptin; nanoparticles; antibacterial; nanotechnology

\section{Introduction}

Infectious diseases are a significant burden on public health, driven largely by socio-economic, environmental and ecological factors [1]. About 15 million of 57 million annual deaths worldwide are estimated to be caused by infectious diseases, principally due to bacterial pathogens [1]. The burden of morbidity and mortality falls most heavily on people in developing countries [2]. Drug-resistant microbes are a major factor causing microbial re-emergence [3]. Among numerous bacteria, Escherichia coli, Staphylococcus aureus, Pseudomonas aeruginosa, Bacillus species, Klebsiella pneumoniae 
are important human pathogens contributing to urinary tract infections, neonatal meningitis, gastroenteritis, wound and skin diseases, food poisoning and nosocomial infections [4-10]. The overuse of antibiotics has contributed to bacterial acquisition of drug resistance resulting in reduced efficacy of available drugs.

During the past decade, nanomedicine has shown great potential due to effectiveness of various nanoconjugates against pathogenic microbes [11]. Nanomaterials have been frequently used as effective coatings to prevent bacterial adhesion to surfaces as well as bactericidal agents [12]. He et al., showed the development of self-defensive and antibacterial adhesion surface coating based on bilayer hydrogel which can promote cell adhesion and proliferation [13,14]. Polymers-based antibacterial agents are also an important class of nanomaterials. Yuan et al. reported various types of hydroxyl-rich cationic derivatives of star-like poly (glycidyl methacrylate) as broad-spectrum antibacterial and antifouling surface coating agents [15]. Antibacterial activity of low molecular weight cationic polymers is shown to affect the membrane permeability and disruption against a broad range of bacteria [16]. In another report, a salivary statherin protein inspired poly(amidoamine) dendrimer is shown to exhibit antibacterial effects as effective coating on hydroxyapatite $[17,18]$. Similarly, dendrons have been shown as a clicking tool for generating nonleaching antibacterial materials [19]. Metal nanoparticles have been studied extensively because of their unique physicochemical characteristics including catalytic activity, optical properties, electronic properties, antimicrobial activity, and magnetic properties [20]. Among these, silver nanoparticles (AgNPs) have shown growth inhibitory as well as bactericidal effects [21]. The high surface area of AgNPs leads to high antimicrobial activity as compared with the silver metal [22]. With the limited discovery of novel antibacterial agents, a feasible approach is to modify clinically approved drugs to enhance their efficacy and/or drug repurposing to expedite discovery of effective formulation of antibacterial agents.

Cephradine (relative molecular mass $349.406 \mathrm{~g} \mathrm{~mol}^{-1}$ ) is a first generation cephalosporins antibiotic drug that is widely used in the treatment of bacterial infections of the urinary and the respiratory tract, as well as ear, skin and soft tissues. It is used against both Gram-positive and Gram-negative bacteria. Its mode of action is inhibition of bacterial cell wall synthesis [23,24]. Vildagliptin (relative molecular mass $303.399 \mathrm{~g} \mathrm{~mol}^{-1}$ ) is an antidiabetic drug, which is a small molecule and inhibits dipeptidyl peptidase-4 (DPP4). Vildagliptin has been shown to stimulate insulin secretion and inhibit glucagon secretion in a glucose-dependent manner [25-27]. Here we tested whether conjugation of AgNPs can enhance efficacy of the clinically approved drug, Cephradine.

\section{Materials and Methods}

\subsection{Bacterial Cultures}

The cultures of six bacterial isolates including neuropathogenic Escherichia coli K1 (a cerebrospinal fluid isolate from a meningitis patient; 018:K1:H7), strain E44, was used in the present study (Malaysian Type Culture Collection 710859), and methicillin-resistant Staphylococcus aureus (MRSA) was used as described previously (Malaysian Type Culture Collection 381123). The MRSA strain was originally derived from the blood cultures, obtained from the Luton \& Dunstable Hospital NHS Foundation Trust, Luton, England, UK. Pseudomonas aeruginosa, Klebsiella pneumoniae, Bacillus cereus and Streptococcus pyogenes were obtained from the Microbiology Research Laboratory at Sunway University. Stock cultures were refreshed by subculturing every 15 days on nutrient agar plates and were maintained at $4{ }^{\circ} \mathrm{C}$.

\subsection{Synthesis of AgNPs Coated with Drugs}

Cephradine conjugated silver nanoparticles (Ceph-AgNPs) were synthesized. Briefly, $5 \mathrm{~mL}$ $(0.1 \mathrm{mM})$ Cephradine aqueous solution was reacted with $5 \mathrm{~mL}(0.1 \mathrm{mM})$ silver nitrate aqueous solution, and the reaction mixture was magnetically stirred for $10 \mathrm{~min}$. Twenty $\mu \mathrm{L}$ of $5 \mathrm{mM}$ freshly prepared Sodium borohydride aqueous solution $\left(\mathrm{NaBH}_{4}\right)$ was added in the above stirring 
reaction mixture. The color of solution turned yellow-brown from transparent upon addition of a reducing agent indicating the reduction of silver ions and the formation of Ceph-AgNPs [28,29]. For Vildagliptin-conjugated silver nanoparticles (Vgt-AgNPs), a similar procedure was repeated by optimizing different volume ratio $(v / v)$ of silver solution and drugs. Stable Vgt-AgNPs were obtained at respective $v / v$ of silver to drug at 1:1. The amount of drug loaded on the nanoparticles was also measured. Nanoparticles were centrifuged at $12,000 \times g$ for $1 \mathrm{~h}$, supernatant was collected, freeze-dried, and the unloaded drugs was determined by weighing. The results are expressed as the percentage of the drug amount contained in $100 \mathrm{mg}$ of the dried nanoparticle. The percentage of drug loading on nanoparticles was found to be $52 \%$ and $68 \%$ for Ceph-AgNPs and Vgt-AgNPs, respectively.

\subsection{Characterization of AgNPs-Coated Drugs}

After successful synthesis of nanoconjugates, Ceph-AgNPs and Vgt-AgNPs were subjected to complete analysis via ultraviolet-visible spectrophotometry (UV-vis), Fourier transformation infrared (FT-IR), atomic force microscopy (AFM), and dynamic light scattering (DLS) as described previously [28,29].

\subsection{Bactericidal Assay}

Antibacterial potential of AgNPs, Ceph and Ceph-AgNPs was determined by using bactericidal assay [30]. Briefly, bacterial cultures were adjusted to optical density (OD) of 0.22 at $595 \mathrm{~nm}$ using a spectrophotometer $\left(\mathrm{OD}_{595}=0.22\right)$ which corresponds to $10^{8}$ colony-forming units per $\mathrm{mL}\left(\right.$ C.F.U. $\left.\mathrm{mL}^{-1}\right)$. An inoculum of $10 \mu \mathrm{L}$ of above bacteria culture (equivalent to approximately $10^{6}$ C.F.U.) was incubated with various concentrations of either Ceph-AgNPs, and Vgt-AgNPs in $1.5 \mathrm{~mL}$ centrifuge tubes at $37^{\circ} \mathrm{C}$ for $2 \mathrm{~h}$. For negative controls untreated bacterial culture were incubated with phosphate buffer saline (PBS). Vildagliptin and Cephradine alone were used as additional controls, while bacteria incubated with $100 \mu \mathrm{g} \mathrm{mL}^{-1}$ of gentamicin were used as positive control. Next, bacteria were serially diluted and $10 \mu \mathrm{L}$ of each dilution was plated on nutrient agar plates. These plates were incubated at $37^{\circ} \mathrm{C}$ overnight, followed by viable bacterial C.F.U. count.

\subsection{Cytopathogenicity Assay}

Cytopathogenicity assays were performed as described previously [31]. Briefly, E. coli K1 were incubated with various concentrations of Cephradine, Vildagliptin, and their nanoconjugates for $2 \mathrm{~h}$ at $37^{\circ} \mathrm{C}$. Next, all test samples were incubated with confluent HeLa monolayers in supplemented medium. Plates were incubated at $37^{\circ} \mathrm{C}$ for $24 \mathrm{~h}$ in a $5 \% \mathrm{CO}_{2}$ incubator and observed for cytotoxic effects. At the end of this incubation period, the supernatants were collected and cytopathogenicity was detected by measuring lactate dehydrogenase (LDH) release (Cytotoxicity Detection kit) as follows: $\%$ cytotoxicity $=($ sample value - control value $) /$ total LDH release - control value $) \times 100$. Control values were obtained from host cells incubated in RPMI-1640 medium alone. Total LDH release was determined from HeLa cells treated with $1 \%$ Triton X-100 for $30 \mathrm{~min}$ at $37^{\circ} \mathrm{C}$. The basis of this assay is that cell supernatant containing LDH catalyzes the conversion of lactate to pyruvate, generating reduced form of nicotinamide adenine dinucleotide (NADH) and $\mathrm{H}^{+}$. In the second step, the catalyst (diaphorase, solution from kit) transfers $\mathrm{H}$ and $\mathrm{H}^{+}$from NADH and $\mathrm{H}^{+}$to the tetrazolium salt p-iodo-nitrotetrazolium violet (INT), which is reduced to formazan (dye), and absorbance is read at $490 \mathrm{~nm}$.

\section{Results}

\subsection{Characterization of Cephradine and Vildagliptin Coated Silver Nanoparticles}

The UV-vis spectra of both silver-drug nanoconjugates showed characteristic surface plasmon resonance band in the range of 400-450 nm. AFM images were recorded to ascertain the morphology of these nanoparticles. The representative topographical images of Ceph-AgNPs and Vgt-AgNPs revealed the formation of spherical nanoparticles (Figure 1a,b). The size distribution of drugs nanoconjugates 
was determined by DLS (Figure 1c,d). Vgt-AgNPs was found to be a mixture of small and large particle size ranging from 2, 7, and $90 \mathrm{~nm}$ with an average size of $33 \mathrm{~nm}$, as compared to Ceph-AgNPs (average size $85 \mathrm{~nm}$ ). FT-IR analysis demonstrated the involvement of hydroxyl groups in both drugs in the stabilization of silver nanoparticles (Figure 2).
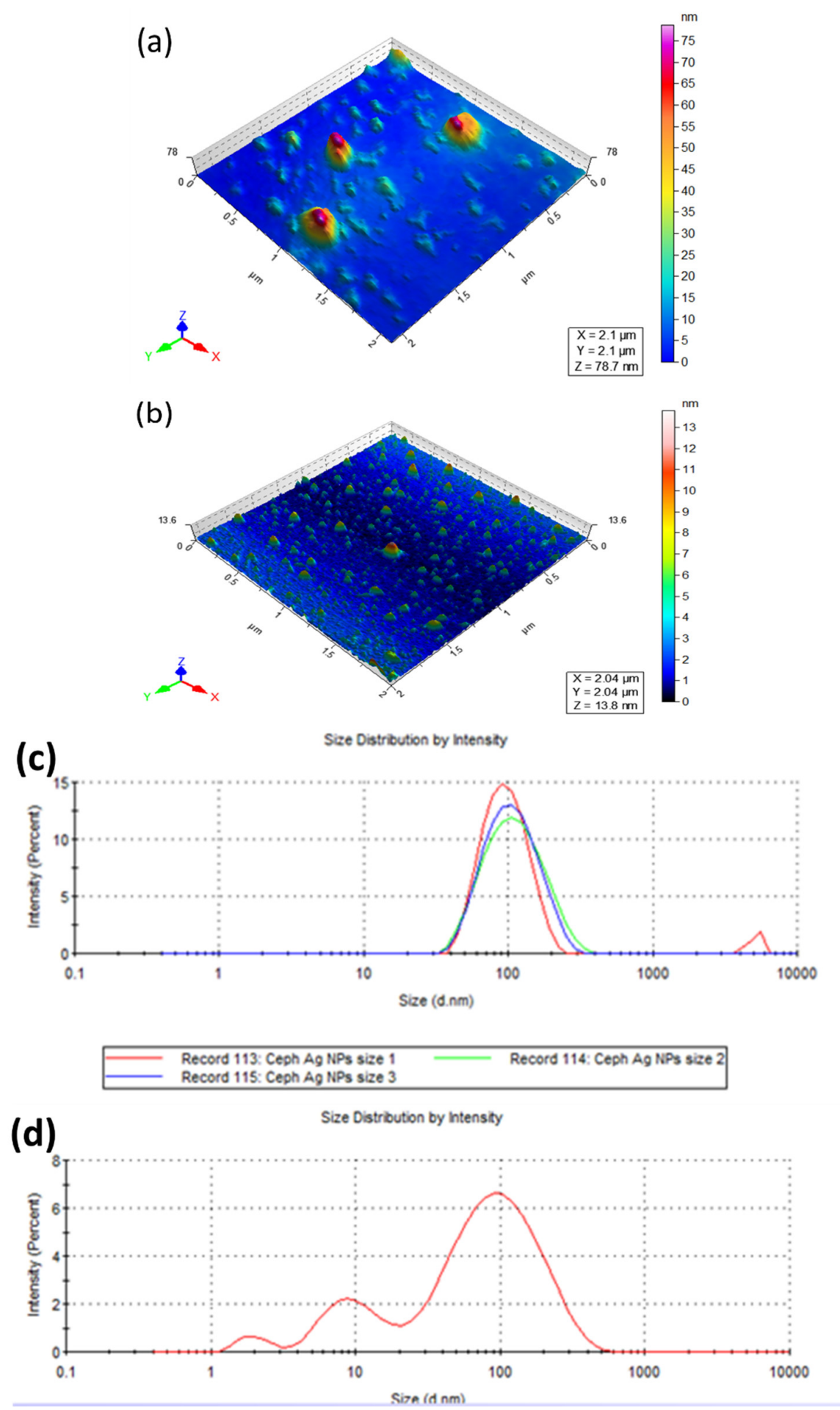

Figure 1. Representative images of atomic force microscopy (AFM) of Ceph-AgNPs (a); Vgt-AgNPs (b); AFM topographs were recorded on Agilent 5500 instrument used in tapping mode with silicon nitride cantilever. Ceph-AgNPs were found to be $85 \mathrm{~nm}$ (c); whereas, Vgt-AgNPs with the size distribution of $33 \mathrm{~nm}$ as measured by DLS (d). Both nanoparticles were spherical and polydisperesed. 
(a)
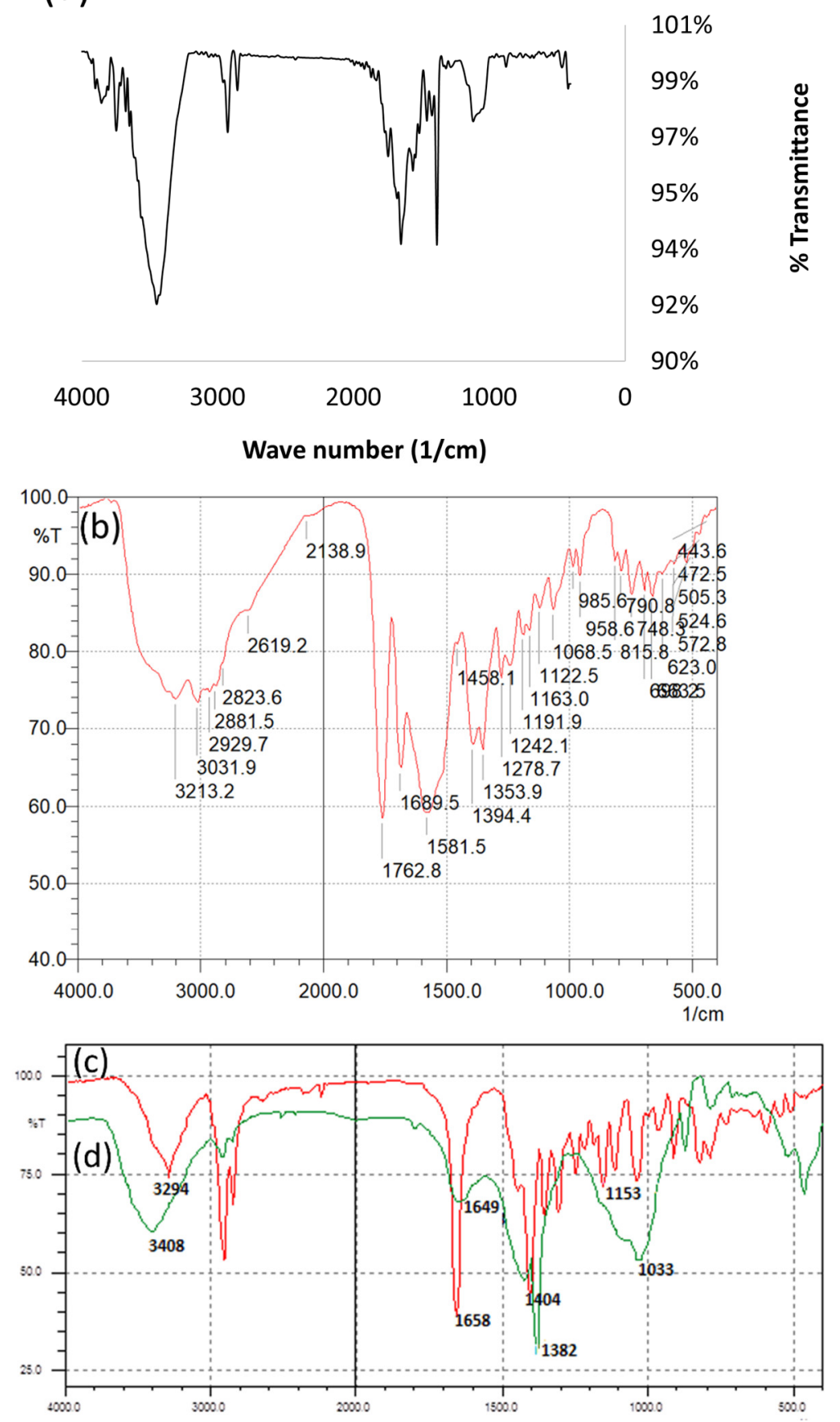

Figure 2. Representative spectra of FT-IR of Ceph-AgNPs (a); Vgt-AgNPs (b); shows the presence of hydroxyl, lactam, carboxylic acid and amino groups. However, while compared with drugs alone (c,d), hydroxyl groups peaks showed a shift in wave number which indicates the interaction with silver nanoparticles. Spectra were recorded at Bruker Vector 22 instrument using Potassium bromide (KBr) disc method.

3.2. Cephradine and Vildagliptine Conjugated with AgNPs Exhibited Increased Bactericidal Effects against E. coli K1 and MRSA Compared with AgNPs and Drugs Alone

Bactericidal assay was performed to determine the effects of drugs conjugated with AgNPs and drugs alone on E. coli $\mathrm{K} 1$ and MRSA. The concentrations of samples were adjusted to achieve MIC50 (minimum inhibitory concentration to kill 50\% bacteria), which can be observed in MRSA and S. pyogense, and in the rest of bacteria MIC90 (minimum inhibitory concentration to kill 90\% bacteria) 
is observed at tested concentrations. The results revealed that both drugs conjugated with AgNPs exhibited significant bactericidal effects ( $p<0.05$ using $t$-test, two-tailed distribution). In addition, treatment with bare AgNPs alone had limited effects on E. coli K1 and MRSA (Figure 3). Notably, Ceph-AgNPs showed significant bactericidal effects at 5 and $10 \mu \mathrm{M}$ compared with drugs alone $(p<0.05)$. Vildagliptin alone did not show significant bactericidal effects at 5 or $10 \mu \mathrm{M}$, while, at 5 and $10 \mu \mathrm{M}$, Vgt-AgNPs, bacteria were significantly reduced (from $7.3 \times 10^{7}$ to $5.4 \times 10^{5}$ ) and (from $8.6 \times 10^{7}$ to $4.8 \times 10^{5}$ ) respectively for Gram-negative E. coli K1, and (from $1.0 \times 10^{7}$ to $4.3 \times 10^{6}$ ) (from $9.3 \times 10^{6}$ to $2.3 \times 10^{6}$ ) at 5 and $10 \mu \mathrm{M}$ for Gram-positive MRSA (Figure 3).

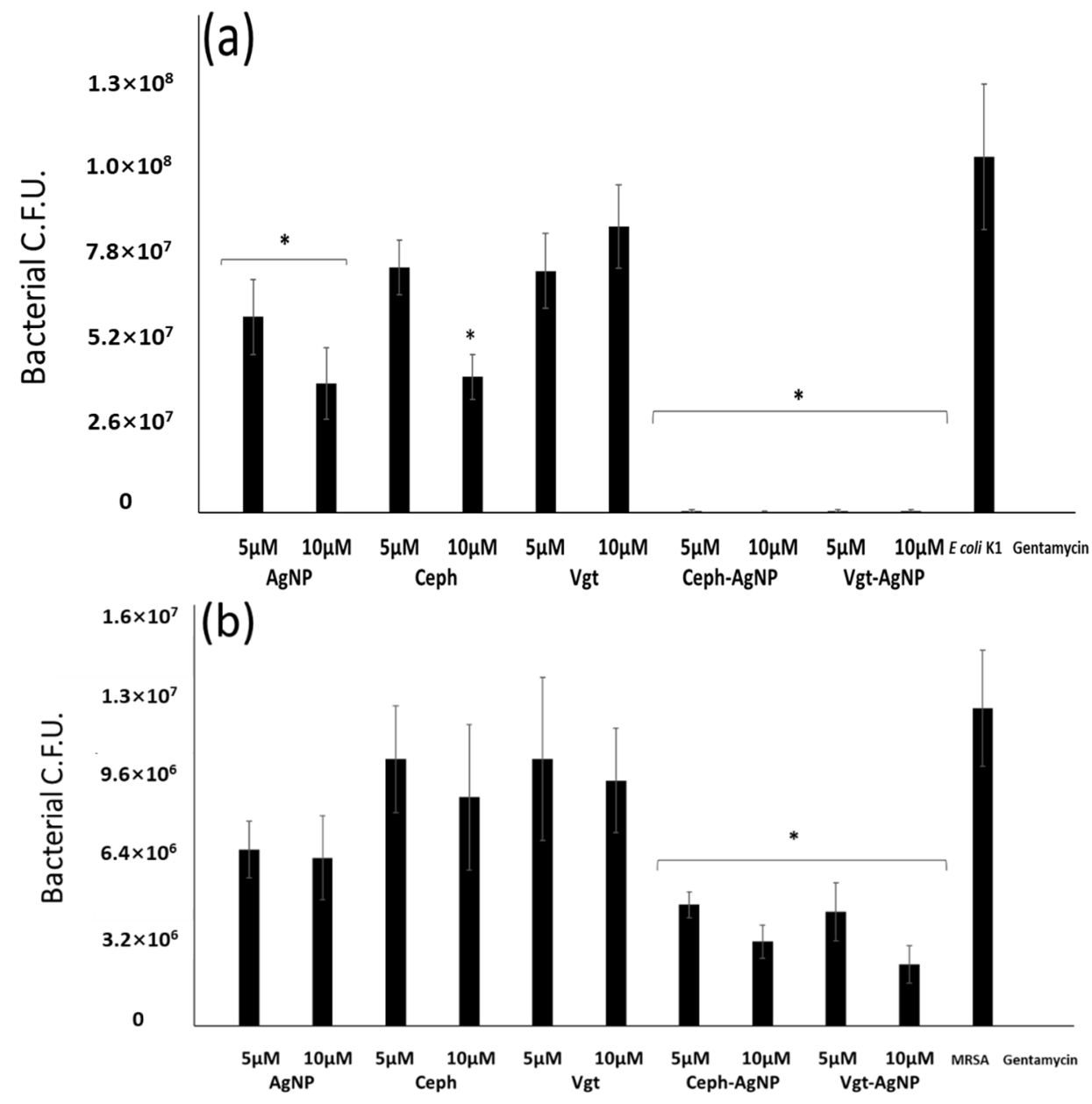

Figure 3. E. coli K1 (a); MRSA (b); colonies were determined following incubation with drugs alone, Ag alone, AgNPs conjugated with drugs. Briefly, $1 \times 10^{6}$ E. coli $\mathrm{K} 1$, MRSA colonies were incubated with drugs and controls at $37^{\circ} \mathrm{C}$ for $24 \mathrm{~h}$. Next, colonies were accounted. Both drug-conjugated AgNPs exhibited significant bactericidal effects $(p<0.05$ using $t$-test, two-tailed distribution, as indicated by asterisk). The results are the mean \pm standard error of three independent experiments performed in duplicate.

3.3. Cephradine and Vildagliptine Conjugated with AgNPs Exhibited Increased Bactericidal Effects against P. aeruginosa, K. pneumoniae, B. cereus, S. pyogenes Compared with the Drugs Alone

The results revealed that drugs conjugated with AgNPs exhibited significant bactericidal effects at 1 - and $2-\mu \mathrm{M}$ concentration against P. aeruginosa, K. pneumoniae, B. cereus, S. pyogenes ( $p<0.05$ using $\mathrm{T}$ test and two-tailed distribution). However, at $1 \mu \mathrm{M}$ and $2 \mu \mathrm{M}$ concentration, the treatment with AgNPs alone had similar effects on the number of bacteria. Notably, Ceph-AgNPs and Vgt-AgNPs showed significant effects at $1 \mu \mathrm{M}$ and $2 \mu \mathrm{M}$ compared with the drugs alone (Figure 4 ). 

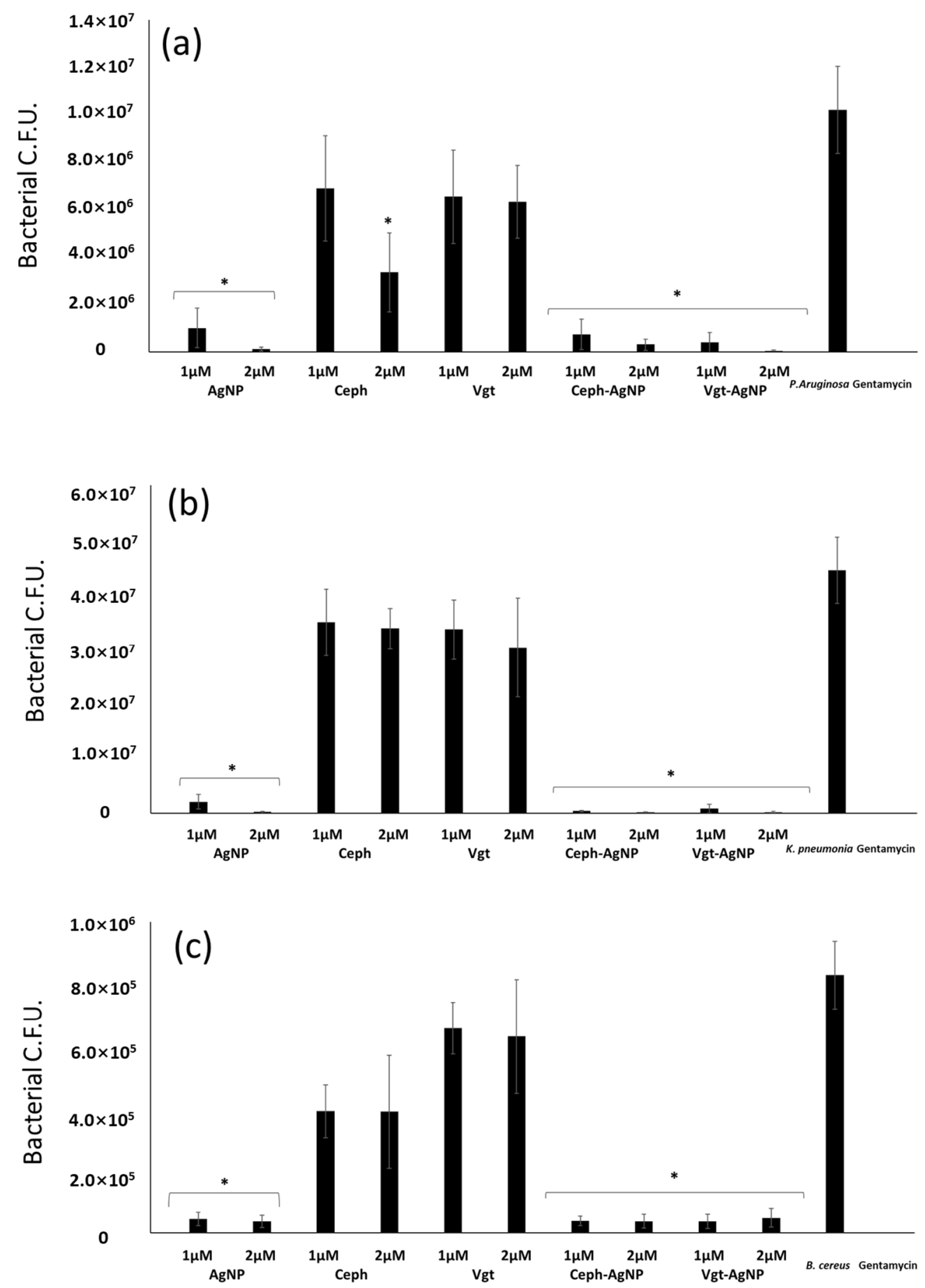

Figure 4. Cont. 


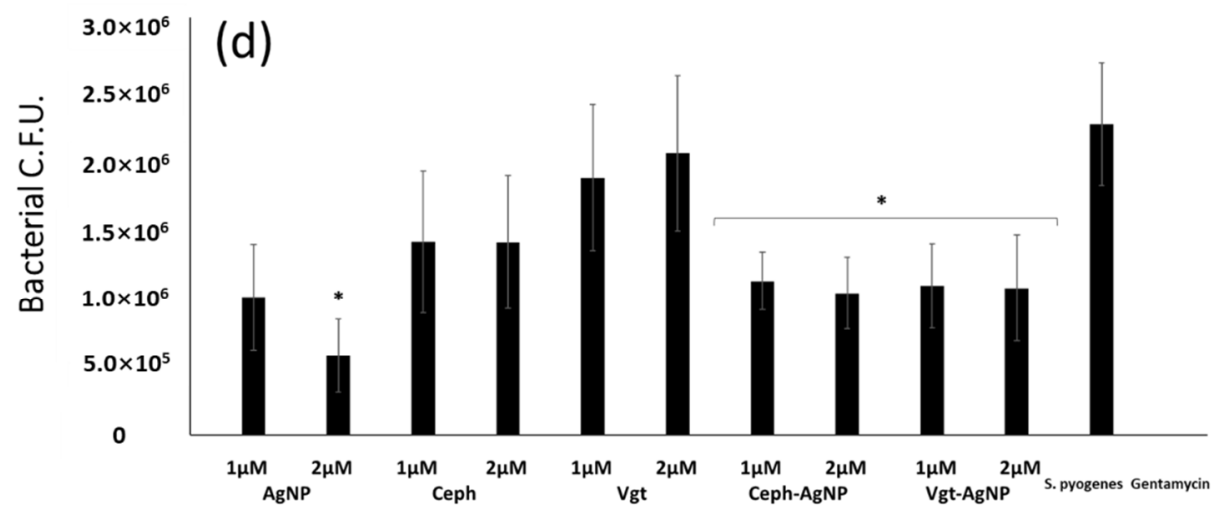

Figure 4. P. aeruginosa (a); K. pneumoniae (b); B. cereus (c); S. pyogenes (d). Bacterial colonies were determined following incubation with Cephradine and Vildagliptine. Briefly, $1 \times 10^{6}$ bacteria were incubated with drugs and controls at $37^{\circ} \mathrm{C}$ for $24 \mathrm{~h}$. Both drugs-conjugated AgNPs and Ag-NPS - alone exhibited significant bactericidal effects $(p<0.05$ using $t$-test, two-tailed distribution, as indicated by asterisk), while as there was no significant effects of drugs alone. The results are the mean \pm standard error of three independent experiments performed in duplicate.

\subsection{Silver Nanoparticle-Conjugated Drugs Inhibited E. coli K1-Mediated Host Cell Cytotoxicity}

To determine whether AgNP-conjugated drugs inhibited bacteria-mediated host cell cytotoxicity, assays were performed by incubating $10^{6}$ E. coli $\mathrm{K} 1$ with HeLa cells for $24 \mathrm{~h}$. E. coli $\mathrm{K} 1$ alone produced $60 \%$ host cell death. On the other hand, bacteria pretreated with AgNPs as well as Ceph-AgNPs and Vgt-AgNPs caused minimal host cell damage and host cell cytotoxicity was reduced to less than 15\% (Figure 5). These findings also showed that Ceph-AgNPs and Vgt-AgNPs alone had minimal host cell cytotoxicity.

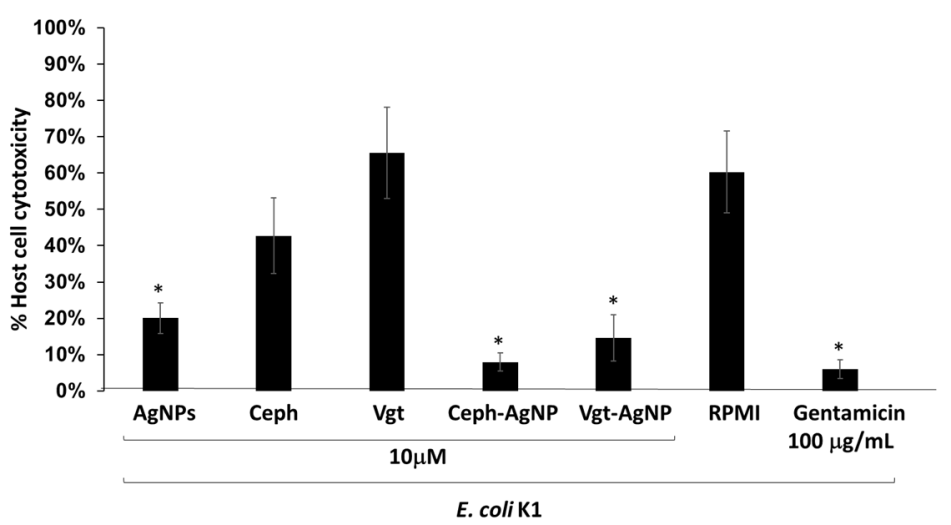

Figure 5. Cytopathogenicity assays were performed using E. coli $\mathrm{K} 1$ as described in materials and methods. Briefly, bacteria were incubated with test samples for $2 \mathrm{~h}$ before putting on HeLa cells monolayer with and without different drugs $(10 \mu \mathrm{M})$, Cephradine (Ceph) and Vildagliptine (Vgt). Cells were then incubated for $24 \mathrm{~h}$ on standard conditions. Untreated bacteria, and bacteria treated with gentamicin were also treated with cells to evaluate their effects on cells cytotoxicity. Triton- $X$ was used to lyse cells before determination of lactate dehydrogenase (LDH) release as marker of cell damage. LDH was determined by using Roche applied sciences LDH kit supplemented with enzyme and buffer. The \% cytotoxicity was calculated by formula: $\%$ cytotoxicity $=($ sample value - control value $) /$ total $\mathrm{LDH}$ release - control value) $\times 100$. The results are representative of at least three independent experiments performed in duplicates. Asterisk indicates $p<0.05$ using $t$-test, two-tailed distribution.

\section{Discussion}

The lack of development and approval of new and effective antibacterials as well as growing MDR microbes presents a major challenge in our ability to counter bacterial infections [31]. Nanotechnology 
offers great promise in the field of biomedicines, especially diagnosis and drug delivery. It offers opportunities for therapeutic agent delivery to specific cells and receptors. Nanomaterial-based drug delivery systems have the potential to improve pharmacokinetics and pharmacodynamics of the drugs [32]. The small size of nanoparticles provides them a greater surface area for maximum drug loading as well as high accessibility for specific targets. Recently, various drug-conjugated nanoparticles are being developed against infections caused by resistant microbes [33]. The most common metal carriers for nanoparticle-based drug delivery systems include gold, silver, and iron oxide due to their inertness and biocompatibility [33].

Though the mode of action of silver nanoparticles on the bacteria has been suggested to affect morphological and structural changes in the bacterial cells, the large surface area, provides better uptake by microorganisms [34]. Hence, silver nanoparticles have the ability to anchor to the bacterial cell wall and subsequently penetrate it, thereby causing structural changes leading to increased permeability of the cell membrane and cell death. In addition, the formation of free radicals by the silver nanoparticles have the ability to damage the cell membrane and make it porous resulting in bacterial cell death [35]. The bacterial membrane contains sulfur-containing proteins and the AgNPs interact with these proteins in the cell as well as with the phosphorus containing compounds. When AgNPs enter the bacterial cell, it forms a low molecular weight region in the center of the bacteria to which the bacteria conglomerates thus protecting the DNA from silver ions. Also, it generates reactive oxygen species, which are produced to attack the respiratory chain, cell division, and finally leading to cell death [36].

Silver conjugated Cephradine (mode of action involves binding and inactivation penicillin binding proteins leading to inhibition of peptidoglycan layer and causing cell lysis) and Vildagliptin (DPP4 inhibitor) were synthesized by reducing silver nitrate with sodium borohydride in the presence of drugs. These nanodrug conjugates were characterized by UV-visible spectrophotometry, FT-IR spectroscopy, and AFM. Cephradine and Vildagliptin successfully stabilized AgNPs and displayed surface plasmon resonance band in the range of $400-450 \mathrm{~nm}$. FT-IR analysis showed the interaction of hydroxyl groups of drugs with silver nanoparticles for stabilization. Hence, the mode of stabilization is anticipated to be noncovalent interactions. Ceph-AgNPs and Vgt-AgNPs both were found to be spherical in shape and lie in a range of size distribution from 30-80 nm. Ceph-AgNPs were larger as compared to Vgt-AgNPs.

After characterization, these nanoparticles were subjected to antibacterial assays. Ceph-AgNPs and Vgt-AgNPs showed significant bactericidal effects against Gram-negative E. coli K1, P. aeruginosa, K. pneumonia and Gram-positive MRSA, B. cereus, and S. pyogenes. Nevertheless, these findings show tremendous potential in the development of new antibacterial formulations. As discussed previously, Cephradine is a cephalosporin first-generation antibiotic, which is not very effective against a number of bacteria because the different resistance mechanisms varied from the variation of the penicillin-binding protein, production of $\beta$-lactamase, existence of $\beta$-lactamase genes on plasmids or on bacterial chromosomes, and efflux pump mechanisms. For instance, MRSA produces abnormal penicillin binding protein $2 \mathrm{~A}$, which has low methicillin affinity (mediated through the mec $A$ gene), which is carried on the staphylococcal cassette chromosome mec (SCCmec) by horizontal gene transfer and this results in resistance to Cephradine as an antibiotic [37]. Ceph-AgNPs provide a change in susceptibility of the drug along with, presumably, enhanced bioavailability. On the other hand, Vildagliptin (dipeptidyl peptidase-4 inhibitor) and its silver nanoparticles showed some promising effects as an antibacterial. Furthermore, these nanoparticles significantly and selectively reduced the pathogen-mediated host cell cytotoxicity caused by Gram-negative bacteria.

Drug-loaded nanoparticles enter in the bacteria by endocytosis showing either specific or non-specific type of interactions with cell membrane [38]. The positive charge of AgNPs interacts with lipopolysaccharides of Gram-negative bacteria with more affinity than the cellular wall of Gram-positive bacteria, that possess few sites for interactions, then releases the drugs intracellularly [38]. In previous reports, cephalosporin conjugated with AgNPs also showed 
enhancement in the antibacterial potency of Ceftriaxone and Cefixime against E. coli and S. pyogenes, respectively [39,40]. In conclusion, Cephradine and Vildagliptin showed bactericidal effects against the six tested bacteria in this study, but their conjugation with AgNPs enhanced their antibacterial efficacy. Moreover, Ceph-AgNPs and Vgt-AgNPs also significantly reduced the host cells cytotoxicity. The exact mechanism of action of these nanoparticles is not precisely understood and it is the subject of future studies along with testing their potential in vivo.

Author Contributions: Conceptualization, N.A.K., R.B.S., M.R.S.; Methodology, A.M., A.A. and D.A.; Software, A.M., D.A.; Validation, A.A., R.B.S. and N.A.K.; Formal Analysis, A.M. and A.A.; Investigation, A.M.; Resources, N.A.K.; Data Curation A.M., D.A.; Writing-Original Draft Preparation, A.M. and A.A.; Writing-Review \& Editing, N.A.K. and R.B.S.; Visualization, M.R.S.; Supervision, R.B.S.; Project Administration, R.B.S.; Funding Acquisition, R.B.S.

Funding: This work is supported by University Research Award INT-2017-03 by Sunway University, Malaysia.

Acknowledgments: We are thankful to Sunway University for support.

Conflicts of Interest: The authors declare that they have no competing interests.

\section{References}

1. Garchitorena, A.; Sokolow, S.H.; Roche, B.; Ngonghala, C.N.; Jocque, M.; Lund, A.; Barry, M.; Mordecai, E.A.; Daily, G.C.; Jones, J.H.; et al. Disease ecology, health and the environment: A framework to account for ecological and socio-economic drivers in the control of neglected tropical diseases. Philos. Trans. R. Soc. B 2017, 372, 20160128. [CrossRef] [PubMed]

2. Wang, Y.; Yu, L.; Kong, X.; Sun, L. Application of nanodiagnostics in point-of-care tests for infectious diseases. Int. J. Nanomed. 2017, 12, 4789-4803. [CrossRef] [PubMed]

3. Anuj, S.A.; Gajera, H.P.; Hirpara, D.G.; Golakiya, B.A. Bactericidal assessment of nano-silver on emerging and re-emerging human pathogens. J. Trace Elem. Med. Biol. 2018. [CrossRef] [PubMed]

4. Alanis, A.J. Resistance to antibiotics: Are we in the post-antibiotic era? Arch. Med. Res. 2005, 36, 697-705. [CrossRef] [PubMed]

5. Demain, A.L.; Sanchez, S. Microbial drug discovery: 80 years of progress. J. Antibiot. 2009, 62, 5-16. [CrossRef] [PubMed]

6. Nikaido, H. Multidrug resistance in bacteria. Annu. Rev. Biochem. 2009, 78, 119-146. [CrossRef] [PubMed]

7. Lee, K.; Silva, E.A.; Mooney, D.J. Growth factor delivery-based tissue engineering: General approaches and a review of recent developments. J. R. Soc. Interface 2011, 8, 153-170. [CrossRef] [PubMed]

8. Pantosti, A.; Venditti, M. What is, M.R.SA? Eur. Respir. J. 2009, 34, 1190-1196. [CrossRef] [PubMed]

9. Granum, P.E.; Lund, T. Bacillus cereus and its food poisoning toxins. FEMS Microbiol. Lett. 1997, 157, $223-228$. [CrossRef] [PubMed]

10. Podschun, R.; Ullmann, U. Klebsiella spp. as nosocomial pathogens: Epidemiology, taxonomy, typing methods, and pathogenicity factors. Clin. Microbiol. Rev. 1998, 11, 589-603. [CrossRef] [PubMed]

11. Naqvi, S.Z.; Kiran, U.; Ali, M.I.; Jamal, A.; Hameed, A.; Ahmed, S.; Ali, N. Combined efficacy of biologically synthesized silver nanoparticles and different antibiotics against multidrug-resistant bacteria. Int. J. Nanomed. 2013, 8, 3187-3195. [CrossRef] [PubMed]

12. Grace, J.L.; Elliott, A.G.; Huang, J.X.; Schneider, E.K.; Truong, N.P.; Cooper, M.A.; Li, J.; Davis, T.P.; Quinn, J.F.; Velkov, T.; et al. Cationic acrylate oligomers comprising amino acid mimic moieties demonstrate improved antibacterial killing efficiency. J. Mater. Chem. B 2017, 5, 531-536. [CrossRef] [PubMed]

13. Dai, T.; Wang, C.; Wang, Y.; Xu, W.; Hu, J.; Cheng, Y. A Nanocomposite Hydrogel with Potent and Broad-Spectrum Antibacterial Activity. ACS Appl. Mater. Interfaces 2018. [CrossRef] [PubMed]

14. He, M.; Wang, Q.; Zhao, W.; Li, J.; Zhao, C. A self-defensive bilayer hydrogel coating with bacteria triggered switching from cell adhesion to antibacterial adhesion. Polym. Chem. 2017, 8, 5344-5353. [CrossRef]

15. Yuan, H.; Yu, B.; Fan, L.H.; Wang, M.; Zhu, Y.; Ding, X.; Xu, F.J. Multiple types of hydroxyl-rich cationic derivatives of, P.G.MA for broad-spectrum antibacterial and antifouling coatings. Polym. Chem. 2016, 7, 5709-5718. [CrossRef] 
16. Grace, J.L.; Huang, J.X.; Cheah, S.E.; Truong, N.P.; Cooper, M.A.; Li, J.; Davis, T.P.; Quinn, J.F.; Velkov, T.; Whittaker, M.R. Antibacterial low molecular weight cationic polymers: Dissecting the contribution of hydrophobicity, chain length and charge to activity. RSC Adv. 2016, 6, 15469-15477. [CrossRef] [PubMed]

17. Gou, Y.; Yang, X.; He, L.; Xu, X.; Liu, Y.; Liu, Y.; Gao, Y.; Huang, Q.; Liang, K.; Ding, C.; et al. Bio-inspired peptide decorated dendrimers for a robust antibacterial coating on hydroxyapatite. Polym. Chem. 2017, 8, 4264-4279. [CrossRef]

18. Rabanal, F.; Grau-Campistany, A.; Vila-Farrés, X.; Gonzalez-Linares, J.; Borràs, M.; Vila, J.; Manresa, A.; Cajal, Y. A bioinspired peptide scaffold with high antibiotic activity and low in vivo toxicity. Sci. Rep. 2015, 5, 10558. [CrossRef] [PubMed]

19. Bakhshi, H.; Agarwal, S. Dendrons as active clicking tool for generating non-leaching antibacterial materials. Polym. Chem. 2016, 7, 5322-5330. [CrossRef]

20. Daniel, M.C.; Astruc, D. Gold nanoparticles: Assembly, supramolecular chemistry, quantum-size-related properties, and applications toward biology, catalysis, and nanotechnology. Chem. Rev. 2004, 104, 293-346. [CrossRef] [PubMed]

21. Morones, J.R.; Elechiguerra, J.L.; Camacho, A.; Holt, K.; Kouri, J.B.; Ramírez, J.T.; Yacaman, M.J. The bactericidal effect of silver nanoparticles. Nanotechnology 2005, 16, 2346-2353. [CrossRef] [PubMed]

22. Shahverdi, A.R.; Fakhimi, A.; Shahverdi, H.R.; Minaian, S. Synthesis and effect of silver nanoparticles on the antibacterial activity of different antibiotics against Staphylococcus aureus and Escherichia coli. Nanomed. Nanotechnol. Biol. Med. 2007, 3, 168-171. [CrossRef] [PubMed]

23. Fernandes, R.; Amador, P.; Prudêncio, C. $\beta$-Lactams: Chemical structure, mode of action and mechanisms of resistance. Rev. Med. Microbiol. 2013, 24, 7-17. [CrossRef]

24. Barza, M.; Miao, P.V. Antimicrobial spectrum, pharmacology and therapeutic use of antibiotics. Part 3: Cephalosporins. Am. J. Health-Syst. Pharm. 1977, 34, 621-629.

25. Ahrén, B.; Schweizer, A.; Dejager, S.; Villhauer, E.B.; Dunning, B.E. Mechanisms of action of the dipeptidyl peptidase-4 inhibitor vildagliptin in humans. Diabetes Obes. Metab. 2011, 13, 775-783. [CrossRef] [PubMed]

26. Waghulde, M.; Naik, J. Comparative study of encapsulated vildagliptin microparticles produced by spray drying and solvent evaporation technique. Dry. Technol. 2017, 35, 1644-1654. [CrossRef]

27. Nauck, M. Incretin therapies: Highlighting common features and differences in the modes of action of glucagon-like peptide-1 receptor agonists and dipeptidyl peptidase- 4 inhibitors. Diabetes Obes. Metab. 2016, 18, 203-216. [CrossRef] [PubMed]

28. Ahmed, D.; Shah, M.R.; Perveen, S.; Ahmed, S. Cephradine Coated Silver Nanoparticle their Drug Release Mechanism, and Antimicrobial Potential against Gram-Positive and Gram-Negative Bacterial Strains through AFM. J. Chem. Soc. Pakistan 2018, 40, 388-398.

29. Anwar, A.; Khalid, S.; Perveen, S.; Ahmed, S.; Siddiqui, R. Synthesis of 4-(dimethylamino) pyridine propylthioacetate coated gold nanoparticles and their antibacterial and photophysical activity. J. Nanobiotechnol. 2018, 16, 8. [CrossRef] [PubMed]

30. Khan, N.A.; Osman, K.; Goldsworthy, G.J. Lysates of Locusta migratoria brain exhibit potent broad-spectrum antibacterial activity. J. Antimicrob. Chemother. 2008, 62, 634-635. [CrossRef] [PubMed]

31. Ali, S.M.; Siddiqui, R.; Ong, S.K.; Shah, M.R.; Anwar, A.; Heard, P.J.; Khan, N.A. Identification and characterization of antibacterial compound (s) of cockroaches (Periplaneta americana). Appl. Microbiol. Biotechnol. 2017, 101, 253-286. [CrossRef] [PubMed]

32. Zazo, H.; Colino, C.I.; Lanao, J.M. Current applications of nanoparticles in infectious diseases. J. Control. Release 2016, 224, 86-102. [CrossRef] [PubMed]

33. Wilczewska, A.Z.; Niemirowicz, K.; Markiewicz, K.H.; Car, H. Nanoparticles as drug delivery systems. Pharmacol. Rep. 2012, 64, 1020-1037. [CrossRef]

34. Li, W.R.; Xie, X.B.; Shi, Q.S.; Zeng, H.Y.; Ou-Yang, Y.S.; Chen, Y.B. Antibacterial activity and mechanism of silver nanoparticles on Escherichia coli. Appl. Microbiol. Biotechnol. 2010, 85, 1115-1122. [CrossRef] [PubMed]

35. Prabhu, S.; Poulose, E.K. Silver nanoparticles: Mechanism of antimicrobial action, synthesis, medical applications, and toxicity effects. Int. Nano Lett. 2012, 2, 32. [CrossRef]

36. Rai, M.; Yadav, A.; Gade, A. Silver nanoparticles as a new generation of antimicrobials. Biotechnol. Adv. 2009, 27, 76-83. [CrossRef] [PubMed]

37. De Lencastre, H.; Oliveira, D.; Tomasz, A. Antibiotic resistant Staphylococcus aureus: A paradigm of adaptive power. Curr. Opin. Microbiol. 2007, 10, 428-435. [CrossRef] [PubMed] 
38. Sondi, I.; Salopek-Sondi, B. Silver nanoparticles as antimicrobial agent: A case study on, E. coli as a model for Gram-negative bacteria. J. Colloid Interface Sci. 2004, 275, 177-182. [PubMed]

39. Shah, M.R.; Ali, S.; Ateeq, M.; Perveen, S.; Ahmed, S.; Bertino, M.F.; Ali, M. Morphological analysis of the antimicrobial action of silver and gold nanoparticles stabilized with ceftriaxone on Escherichia coli using atomic force microscopy. New J. Chem. 2014, 38, 5633-5640. [CrossRef]

40. Rasheed, W.; Shah, M.R.; Perveen, S.; Ahmed, S.; Uzzaman, S. Revelation of susceptibility differences due to $\mathrm{Hg}$ (II) accumulation in Streptococcus pyogenes against, C.X.-AgNPs and Cefixime by atomic force microscopy. Ecotoxicol. Environ. Saf. 2018, 147, 9-16. [CrossRef] [PubMed]

(C) 2018 by the authors. Licensee MDPI, Basel, Switzerland. This article is an open access article distributed under the terms and conditions of the Creative Commons Attribution (CC BY) license (http:/ / creativecommons.org/licenses/by/4.0/). 